\title{
The Learning Disciplines for Support Personnel to Build a Learning Organization of Ramkhamhaeng University
}

\section{Duangduen Chancharoen ${ }^{1}$ Chomsupak Cruthaka ${ }^{2 \rtimes}$}

Ramkhamhaeng University, Bangkok, Thailand. Email:duen59@yahoo.com Tel+66949593915

Email.cchomsupak@yahoo.com Tel+66959588409

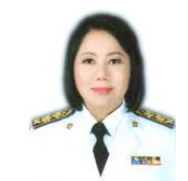

( Corresponding Author

\begin{abstract}
This research aimed primarily at exploring the learning disciplines of support personnel to build a learning organization of Ramkhamhaeng University (RU) and comparing their learning disciplines as categorized by their gender, age, education level, and work experiences. The sample consisted of 334 support personnel of RU. The research tool was a 5-rating scale questionnaire with the reliability coefficient of 0.97 . Statistics used to analyze the data included frequency, percentage, mean, standard deviation, t-test, and One-way Analysis of Variance. The findings revealed the high levels of learning disciplines to build a learning organization (LO) among the support personnel both in the overall aspect and in each of the five dimensions. In addition, the support personnel with different gender and age indicated no significant difference in the overall aspect and in each of the five dimensions regarding their learning disciplines to build a LO. However, the aforesaid difference at 0.05 significant level was found among the support personnel with different education level. Moreover, the support personnel with different work experiences indicated their non-significant differences in terms of the overall, and in the aspects of shared vision and team learning, but reported a significant difference regarding personal mastery, mental models, and systems thinking.
\end{abstract}

Keywords: Learning disciplines, Build a learning organization, Support personnel, Ramkhamhaeng University.

Citation | Duangduen Chancharoen; Chomsupak Cruthaka (2021) The Learning Disciplines for Support Personnel to Build a Learning Organization of Ramkhamhaeng University. Asian Journal of Education and Training, 7(1): 1-6.

History:

Received: 2 November 2020

Revised: 27 November 2020

Acrised: 27 Novemb 2020

Accepted: 17 December 2020

Published: 5 January 2021

Licensed: This work is licensed under a Creative Commons Attribution 3.0 License (oc))

Publisher: Asian Online Journal Publishing Group
Acknowledgement: Both authors contributed to the conception and design of the study.

Funding: This study received no specific financial support.

Competing Interests: The authors declare that they have no conflict of interests.

Transparency: The authors confirm that the manuscript is an honest, accurate, and transparent account of the study was reported; that no vital features of the study have been omitted; and that any discrepancies from the features of the study have been omitted;
study as planned have been explained.

study as planned have been explained.

\section{Contents}

1. Introduction

2. Research Objectives

.2

3. Literature Review

4. Research Methodology .

5. Results

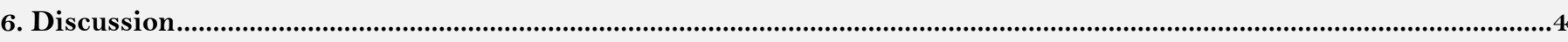

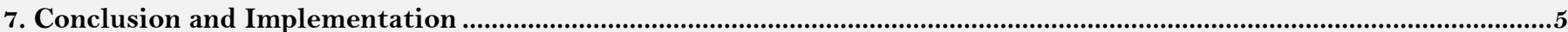

References 


\section{Contribution of this paper to the literature}

This research aimed primarily at exploring the learning disciplines of support personnel to build a learning organization of Ramkhamhaeng University (RU) and comparing their learning disciplines as categorized by their gender, age, education level, and work experiences.

\section{Introduction}

The concept of LO has long been a major key for an organization to keep abreast of changes in the globalized era marked with competitiveness and rapid technological advancement. This concept has later been adopted by government agencies so as to bring forth not only organization development but also human resource development with respect to personnel's knowledge, competency, skills, attitudes, etc.

Hence, organizational management using the concept of LO will enable employees to cultivate self-learning and knowledge sharing throughout the workplace. This will definitely lead an organization to achieve work development efficiency and eventually success in this globalized society.

According to Senge (1990) a LO is a workplace where an individual can continuously build up and extend their creative competency as desired. This type of organization incessantly motivates its employees to be creative and to create unrestricted mutual learning.

RU is administered in a 'knowledge market' type, in which students can obtain their education as deemed appropriate to their own resources. The learning methods are available as either in-class, long distance, or selflearning for students residing in Thailand or overseas. In terms of internal administration, RU is composed of lecturers and support personnel. While the former is in charge of academic tasks, the latter mainly functions to support the former, while simultaneously attempting for self-development to be part of learning organization.

Besides being determined by the university's quality assurance criteria, policy, rules, and regulations, the support personnel are also required to work in cooperation with lecturers, students, and employees of both internal and external offices. Therefore, they need to be a self-learner, rapidly exposed to accurate learning and information, and keep track of any occurring changes both within and outside the university.

As a result, the development of LO is a requisite pathway through which the university's support personnel have to wade. The researcher, therefore, is interested in exploring the development nature of learning organization of RU, aiming particularly to bring forth among the support personnel their individual potentials, work efficiency, as well as constant alert in self-development and self-learning. The research findings will serve as a database for the university executives to formulate efficient policy and strategies in human resource development, so that holistically functions would be conducted to push the whole university to achieve the goal of an effective LO.

\section{Research Objectives}

The objectives of this research are as following:

1. To explore the learning disciplines of support personnel to build a learning organization of RU.

2. To compare the learning disciplines of support personnel to build a learning organization of RU, as categorized by their gender, age, education level, and work experiences.

\section{Literature Review}

Sengé (2006) defined a learning organization as a workplace in which learning is motivated to continually increase personnel competency in the individual, team, and organizational levels, so that the personnel will reach their desirable differing goals. In other words, a LO enhances innovative patterns of thinking, and shares them to all members to create mutual inspiration for mutual and incessant learning throughout the organization.

\subsection{Elements of Learning Organization}

To be a LO, a number of factors are to be developed to promote both internal and external learning, so that the personnel can adjust themselves to the incurring changes. According to Senge (1990) the core elements to build a learning organization consist of five disciplines ) The Fifth Discipline (as following.

(1) Personal mastery: individual learning is the starting point and a baseline to be a LO. Hence, an individual has to force him/herself to be a constant learner as per their personal needs and visions, so as to extend their capability to create efficient work outcomes. Moreover, as suggested by Reece (2004) a mastery person exhibits self-control to attain a high level of learning and self-reflection through constructive criticism and intention to assimilate with the whole organization.

(2) Mental models: this element concerns an individual's holistic perception and understanding of his/her work, together with the ability to build up an interconnectedness across the jobs in the organization. As a result, a positive mental pattern and belief will follow through to generate a constructive mental model in congruence with global visions and realities.

In this aspect, Garvin, Edmondson, and Gino (2008) stated that mental models basically involve an individual's continual scrutinizing of thinking and perception development, coupled with his/her challenges against both ambiguous and vivid existing assumptions about the organization and work environments. In this case, adoption of changes will occur when the organization members develop constructive mental models and consider the organization as part of their learning.

(3) Shared visions: The personnel should be encouraged to build shared visions about the organization's future, and that will reflect their individual's vision. Afterward, thorough communication to pass through the organizations' visions and goals to members from top to bottom levels should be conducted to inflict them into each individual's thinking. In this aspect, shared visions concern members' determination to establish shared goals and implementation to reach these goals. Hence, besides promoting individual and organizational capabilities, the organization itself should facilitate the construction of shared visions among the members of all levels (Chang \& Sun, 2007). 
(4) Team learning: the members should exchange knowledge to build up team learning, and hence team capabilities. Knowledge should be transmitted to create best practices as a work model for other work units. Innovative creativity and invention will also follow suit to generate shared practices. This supports the notion that LO is a place where each member can conduct his/her self-learning.

According to Dyer, Dyer, and Dyer (2013) the context management of highly-efficient team can be achieved by: building team's work goals that are interesting and clearly measurable; making the members confident and understand that efficient team working is a key to achieve those goals; creating a reward system based on team's, not individual's, performances; eliminating obstacles in team working by focusing on formal organizational structures; establishing the organizational culture which supports team work and team behavior; building the information technology system to provide data and information to teams for their decision making; and forming the human resource development system to handle teamwork training, as well as other tasks to support team work, e.g. process of selecting team members.

(5) Systems thinking: this element is the core mechanism of a LO. It supports the notion of learning and sustainable development of human resources in an organization. Systems thinking concerns the continual linkage between acquired knowledge and individual expertise. In this aspect, an individual's holistic ideas will lead to systematic perception of work functions and performances. It also involves logical thinking expressed through thinking pattern and language, and this outcome will definitely and effectively change an organization's work system to coincide with real situations of a LO.

\section{Research Methodology}

The population of this study consisted of 2,929 support personnel of RU in the 2017 fiscal year. The sample size of 353 support personnel was determined by using Taro Yamane's table with $95 \%$ confidence and 0.05 error. The research distributed the questionnaire to the selected sample and got the responses from 334 persons, equaling $94.60 \%$ response rate.

The research tool is a questionnaire invented to explore the learning disciplines of support personnel to build a learning organization of RU. The questionnaire consisted of 2 sections. The first section included five check-list questions asking the sample's personal information, including their gender, age, education level, and work experience. The second section comprised a five-rating scale with items asking about the support personnel's learning disciplines to build a learning organization of RU. The acquired reliability coefficient is 0.97 , signifying that this section is of high reliability,

The collected data were analyzed using frequency and percentage to identify the sample's personal information of gender, age, educational level, and work experiences. Mean and standard deviation were later used to calculate the sample's learning disciplines to build a learning organization of RU. To compare their learning disciplines to build a learning organization of RU across different gender, age, education level, and work experiences, t-test and One-way ANOAVA were conducted. The LSD) Least Significant Differences( would be conducted when the ANOVA yielded a significant result.

\section{Results}

1. The descriptive analysis revealed that half of the support personnel of RU were females $(59.30 \%, n=198)$, with the highest number of those in $31-40$ age group $(36.20 \%, n=121)$, holding a bachelor's degree $(44.9 \%, n=150)$, with 6-10 years of work experiences $(35.50 \%, \mathrm{n}=112)$.

2. The results of learning discipline for support personnel to build a learning organization of RU as shown in Table 1.

3.The inferential analysis was also conducted to compare the learning disciplines of support personnel to build a learning organization of RU, as categorized by their gender, age, education level, and work experiences as shown in Table 2 , Table 3.

Table-1. Mean standard deviation and learning discipline levels for RU support personnel In order to build a learning organization in each aspect.

\begin{tabular}{l|c|c|c}
\hline Learning organization disciplines & $\bar{X}$ & SD & Learning discipline levels \\
\hline 1. Personal mastery & 3.93 & .56 & High \\
\hline 2. Mental models & 3.90 & .54 & High \\
\hline 3. Shared visions & 3.83 & .57 & High \\
\hline 4. Team learning & 3.84 & .58 & High \\
\hline 5. Systems thinking & 3.92 & .59 & High \\
\hline \multicolumn{1}{c|}{ Total } & 3.89 & .48 & High \\
\hline
\end{tabular}

Table 1 The analysis of the learning disciplines of support personnel to build a learning organization of RU, revealed the high levels of learning disciplines to build a learning organization both in the overall aspect and in each of the five dimensions of personal mastery, systems thinking, mental models, team learning, and shared visions, respectively.

Table-2. The comparison of learning discipline for RU support personnel to build a learning organization classified by gender.

\begin{tabular}{|c|c|c|c|c|c|}
\hline \multirow[t]{2}{*}{ Learning organization disciplines } & \multicolumn{2}{|c|}{ Male } & \multicolumn{2}{|c|}{ Female } & \multirow{2}{*}{$\mathbf{t}$} \\
\hline & $\overline{\mathrm{X}}$ & SD & $\overline{\mathrm{X}}$ & SD & \\
\hline 1. Personal mastery & 3.88 & .55 & 3.97 & .57 & 1.419 \\
\hline 2. Mental models & 3.85 & .57 & 3.94 & .51 & 1.425 \\
\hline 3. Shared visions & 3.77 & .61 & 3.86 & .55 & 1.356 \\
\hline 4. Team learning & 3.80 & .58 & 3.87 & .59 & 1.129 \\
\hline 5. Systems thinking & 3.85 & .60 & 3.97 & .57 & 1.718 \\
\hline Total & 3.83 & .48 & 3.92 & .47 & 1.693 \\
\hline
\end{tabular}


Table 2 showed that the overall aspect of learning disciplines to build a LO, the support personnel with different gender indicated no significant difference, while those with different education levels stated a difference at 0.05 significant level.

Table-3. The comparison of learning discipline for RU support personnel to build a learning organization classified by age, education levels and work experiences.

\begin{tabular}{|c|c|c|c|c|}
\hline Source of variance & SS & df & MS & $\mathbf{F}$ \\
\hline \multicolumn{5}{|l|}{$\overline{\text { Age }}$} \\
\hline Between Groups & .594 & 3 & .198 & .878 \\
\hline Within Groups & 74.469 & 330 & .226 & \\
\hline Total & 75.063 & 333 & & \\
\hline \multicolumn{5}{|l|}{ education levels } \\
\hline Between Groups & 3.330 & 2 & 1.665 & $7.682^{*}$ \\
\hline Within Groups & 71.735 & 331 & .217 & \\
\hline Total & 75.063 & 333 & & \\
\hline \multicolumn{5}{|l|}{ work experiences } \\
\hline Between Groups & 2.067 & 4 & .517 & 2.329 \\
\hline Within Groups & 72.996 & 3.29 & .222 & \\
\hline Total & 75.063 & 333 & & \\
\hline
\end{tabular}

Table 3 showed the overall aspect of learning disciplines to build a LO, the support personnel with different age indicated no significant difference, while those with different education levels stated a difference at 0.05 significant level. With regards to the five dimensions (personal mastery, mental model, shared visions, team learning, and systems thinking) of learning disciplines to build a LO, the support personnel with different education levels indicated differences at 0.05 significance level, while those with different age indicated no significant differences. Lastly, the support personnel with different work experiences indicated their non-significant differences in terms of the overall aspect of learning disciplines, and in the aspects of shared visions and team learning, but reported a significant difference regarding personal mastery, mental models, and systems thinking.

\section{Discussion}

The findings revealed the high levels of learning disciplines to build a LO among the support personnel in the overall aspect. The discussions of the said findings in each of the five dimensions of personal mastery, mental models, shared visions, team learning, and systems thinking are as following.

Regarding personal mastery, the research results indicated the support personnel's high level of learning disciplines, with highest mean scores in using new techniques to develop their work, ability of self-learning from various types of media (i.e. books, academic articles, and internet), and continual participating in trainings provided by the university.

The above findings may stem from the fact that the support personnel of RU are required to use their knowledge and ability to achieve successful work performances. Hence, they are well aware of the necessity of selfdevelopment and acquire a body of knowledge from various media types, as well as to apply the available technologies to manage the university's information (rules \& regulations, announcements) via the online system. In addition, efficient organizing of existing knowledge is a key to their effective work performance. Hence, they have to increase their potentials in an incessant manner by participating in a number of training for selfdevelopment and successful application of acquired knowledge to improve their work performances.

The aforesaid findings also coincided with Senge (1990) who considered individual learning as a starting point for an organization to be a learning organization. Hence, an individual should be self-motivated to be a constant learner in accordance with their personal needs. In this aspect, self-control is deemed important for a mastery person to attain a high level of learning (Reece, 2004).

With regards to mental models, the research results indicated the support personnel's high level of learning disciplines, with highest mean scores in linking their thinking to actual performances, having a diversity of perceived thinking and readily in applying it to their work, and being able to efficiently make decision and solve problems in a pressured situations.

This findings may stem from the fact that the support personnel of RU have been striving hard to develop their learning and skills in securing causes and solutions of problems, leading thus to the formation of mental models in preventing the reoccurrence of those problems. They are also able to apply the lessons learned to generate satisfactory performances as perceived by their supervisors, subordinates, and service-recipients who are composed of students, outsiders, and the university personnel.

The above findings also agreed with Garvin et al. (2008) concept regarding the development of mental models from an individual's continual scrutinizing of thinking and perceptions. In addition, Wen (2014) research on "The nature, characteristics and ten strategies of LO" clearly indicated the nature of learning strategies in an organization, and proposed 10 efficient strategies in building up organizational learning in China.

With regards to shared visions, the research results indicated the support personnel's high level of learning disciplines, with highest mean scores in loosing ties with traditional work procedures and opening up for learning innovative work format, considering their work not as an obstacles but an opportunity for work improvement, and using organizational visions as a basis for their works.

The above findings may basically stem from the fact that the support personnel of RU have to mutually take charge in planning and implementing their works in accordance with their unit's policy, ISO 9001: 2000 quality standard system, and academic quality assurance. As a result, they engage in exchanging visions to snatch out better performances, cutting loose their ties with traditional work formats and procedures, leading thus to more efficient work changes.

In addition, the executives also regularly hold formal meetings 2-3 times a month to inform the support personnel about the university's policy. In each work unit, both formal and informal meetings are held in the forms of small talks, discussions, and seminars, to exchange opinions and share visions among colleagues. The support personnel, therefore, are 
able to link shared visions to their work planning and to meet the success goals as determined by their work unit and the university.

The aforementioned findings also coincided with Chang and Sun (2007) conclusion that shared visions concern members' dedication to establish common goals and their use of individual capabilities to reach these goals. In this aspect, Haight (2017) paper on "What do chief learning officers do? An exploratory study of how chief learning officers build learning organizations" reported that shared visions of learning organization among employees were constructed via strategic development and implementation.

In terms of team learning, the research results indicated the support personnel's high level of learning disciplines, with highest mean scores in having co-learning with colleagues to exchange knowledge and work procedures, willing to coaching and exchange learning with others, and having freedom in expressing their thinking and learning with their colleagues.

This finding may stem from the situation in which team learning is basically prevalent in their work units, with an opportunity for the support personnel to express their thinking and ideas in the contexts deemed appropriate. Moreover, cooperation in both routine and non-routine jobs is enhanced in the forms of listening to each other's ideas, discussing, and proposing differing angles to tackle occurring problems. The team learning has basically been enabled particularly under time pressure.

The above findings basically agreed with Willborn and Cheng (1994) who proposed that the strategies to build up a learning organization should start from basic structured and procedures to meet the staff's needs. Hence, the development of team learning activities should be held in the forms of job redesign and work cooperation. In this aspect, Morgan (2017) study on "Influence of six organizational dimensions in an IT organization: A quantitative study" indicated numerous factors leading to the development of a LO, starting from using individual knowledge and abilities, the staff's need to learn, and constructive organizational climate that focuses on team working as well as formal and informal co-learning.

Regarding systems thinking, the research results indicated the support personnel's high level of learning disciplines, with highest mean scores in using past mistakes and success to solve current problems, attempting to plan their own work in agreement with the unit's goals, and exercising systems thinking to create work efficiency.

The above findings may stem from the fact that the support personnel have to perform in accordance with the ISO 9001: 2000 quality standards and academic quality assurance. Hence, they need to exchange visions, discover innovative changes through systems thinking, and exchange information in a systematic manner through their self-created job networks using supportive communication systems via effective technologies.

The findings also agreed with Sengé (2006) idea that supported the significance of systems thinking in the fastchanging and competitive managerial environments. Hence, all executives need to possess intellectual capitals of constructive systems thinking in the form of (1) systematic thinking, with clearly identified goals, diverse means, and visions, and (2) timely thinking about existing realities with no delay in implementation. The findings also supported Luepong (2011) study on development of learning organization in Specialised Financial Institutions (SFIs), that found systems thinking as one of the five disciplines of LO.

The comparative findings revealed the learning disciplines to build a LO among the support personnel as categorized by gender, age, education level, and work experiences as following. Firstly, the support personnel with different gender and age indicated no significant difference in the overall aspect and in each of the five dimensions regarding their learning disciplines to build a learning organization. This finding failed to support the stated hypothesis. This may stem from the fact that the support personnel of RU of both genders and age levels are required to work jointly while sharing their abilities. They also need to perform in accordance with the university policy and job descriptions stated in their routines and non-routines jobs, leading thus to their non-different needs in learning.

Furthermore, it was also found that the support personnel with different education level indicated significant differences in the overall aspect and in each of the five dimensions regarding their learning disciplines to build a LO, hence supporting the stated hypothesis. The said finding may stem from that fact that higher-educated personnel are basically more capable of self-development and opening up for acquiring further knowledge and experiences to be used in their work more efficiently.

Moreover, the support personnel with different work experiences indicated their non-significant differences in terms of the overall aspect of learning disciplines, and in the aspects of shared vision and team learning, but reported a significant difference regarding personal mastery, mental models, and systems thinking. This finding also failed to support the stated hypothesis, and it may stem from the role of an individual's experiences in enabling perception about the university's future pictures. Hence, the said difference may arise out of that particular perception and the encouragement for colleagues to create shared visions and teamwork.

\section{Conclusion and Implementation}

The findings generated from this study, together with relevant academic literature, may serve as a tool to develop learning potentials in individual level, task-related level, and organizational structure level. Moreover, interested parties may apply the said findings to stimulate employees throughout an organization to develop a true learning organization. Hence, related suggestions for further implications are as follows:

1. Personal mastery: The university executives should encourage the support personnel to pursue a higher education level. In addition, they should provide them study trips to open up their new vision. A training institute should also be founded to offer trainings in new knowledge, skills, attitudes, and potentials, so that the support personnel will be a valuable human capital of RU.

2. Mental models: The university executives should support the notion of knowledge management in the organization, particularly the regular exchange of knowledge acquired through participation in trainings, academic conferences, and problem solutions using real case study. This will enable the support personnel to apply their knowledge in a systematic manner.

3. Shared visions: The university executives should empower the support personnel by providing them a challenging job. This deed will definitely uplift their knowledge, capabilities, skills, and job-related expertise to be applied in their work efficiently, with more experts definitely being created in the organization. Besides, the recognition of learning as a key element for a learning organization should also be enhanced via building up 
constructive learning environments on the regularly basis in executive and operational meetings. These activities are expected to generate new knowledge through mutual knowledge exchange, innovative knowledge introduction, arguments, and discussion in complex issues.

4. Team learning: The university executives should support constant team learning via dialogues of small talks and discussions, so as to generate mutual exchanges of knowledge, skills, and expertise. These activities will also redirect the support personnel's attitudes to accept the significance of creative team learning and hence reduce internal conflicts. In addition, all work units should be encouraged to use advanced technology in working, coordinating, transmitting of information, and learning via the e-learning system. The expected outcomes are efficient information search and retrieval to support incessant learning and thus accelerate job success.

5. Systems thinking: The university executives should encourage the support personnel to participate in job-related trainings and systematic thinking. The process may start from planning, executing, auditing \& monitoring, problem solving, and securing advanced technologies to facilitate new knowledge retrieval. The expected outcomes will be effective skills in conceptualization, analysis, synthesis, evaluation, and appropriate adaptation. As a result, the support personnel will develop their thinking and build up their own new knowledge to efficiently achieve job success.

\section{References}

Chang, D.-S., \& Sun, K.-L. (2007). Exploring the correspondence between total quality management and Peter Senge's disciplines of a learning organization: A Taiwan perspective. Total Quality Management Eீ Business Excellence, 18(7), 807-822.Available at: https://doi.org/10.1080/14783360701349914.

Dyer, W. G. J., Dyer, J. H., \& Dyer, W. G. (2013). Team building (5th ed.). San Francisco, CA: Jossey-Bass.

Garvin, D. A., Edmondson, A. C., \& Gino, F. (2008). Is yours a learning organization? Harvard Business Review, 86(3), $109-116$.

Haight, V. D. (2017). What do chief learning officers do? an exploratory study of how chief learning officers build learning organizations (Order No. 10258744). ProQuest Dissertations \& Theses Global. (1875588351).

Luepong, P. (2011). The development of a learning organization model for specialized financial institutions. Dissertations, Doctor of Philosophy, Ramkhamhaeng University.

Morgan, M. A. (2017). Influence of six organizational dimensions in an it organization: A quantitative study (Order No. 10254271). ProQuest Dissertations and Theses Global. (1875238764).

Reece, P. D. (2004). Universities as learning organizations: How can Australian universities become learning organization. Unpublished PhD. Thesis Murdoch University, Australia.

Sengé, P. M. (2006). The fifth discipline: The art छ practice of the learning organization. New York: Doubleday.

Senge, P. M. (1990). The fifth discipline: The art $\mathcal{E}^{2}$ practice of the learning organization. London: Mackays of Chutham plc, Chutham, Kent.

Wen, H. (2014). The nature, characteristics and ten strategies of learning organization. The International Journal of Educational Management, 28(3), 289-298.

Willborn, W., \& Cheng, T. (1994). Global management of quality assurance system. New York: McGraw-Hill. 